\title{
Sex and hand-preference effects in the simultaneous and consecutive discrimination of lifted weight
}

\author{
ERIC E. BRODIE \\ University of Glasgow, Glasgow, Scotland
}

\begin{abstract}
Differential thresholds (DLs) for lifted weight were measured in one-handed consecutive and two-handed simultaneous discrimination paradigms using left- and right-handed, male and female subjects. In one-handed discrimination, no preferred-hand advantage was found for either left- or right-handed subjects. Left-handed subjects were found to perform better than right-handed subjects with both left and right hand. A constant error was found in two-handed simultaneous discrimination, in which the subjects reported that weights felt heavier in one hand than in the other. Neither hand preference nor hand sensitivity was found to correlate with the direction of the error. A sex difference was found in two-handed simultaneous weight discrimination: DLs for male subjects differed between left and right, whereas DLs for female subjects did not. The results are discussed in terms of hemispheric specialization and recent theories of motor control.
\end{abstract}

Manual asymmetry in one-handed weight discrimination has been investigated since the early 19 th century. Weber $(1834 / 1978 a)$ found that weights could be more accurately discriminated when placed on the left hand; he suggested that manual asymmetry occurred because the cutaneous nerves on the left side were more sensitive to pressure than those on the right $(1834 / 1978 a$, p. 57). However, he subsequently withdrew this suggestion $(1846 / 1978 b$, p. 209$)$. More recently, somatosensory studies of the hand have reported no differences between the left hand and the right hand (Corkin, 1978; Corkin, Milner, \& Rasmussen, 1970). Thus, there is no clear evidence to suggest that weight discrimination, when mediated purely by pressure sensing, is better on one side of the body than on the other. However, the discrimination of lifted weight normally depends on both cutaneous and kinesthetic information (Brodie \& Ross, 1984), although the latter does not aid discrimination at low stimulus intensities (Brodie \& Ross, 1986).

Although few studies have compared differential thresholds (DLs) for both left- and right-handed discrimination of lifted weight in a one-handed paradigm, no clear evidence is available in favor of the presence or direction of an asymmetry. Weber (1834/1978a, p. 121) failed to find any difference between left and right hands. Fechner (1860/1966, p. 79), using himself as the subject, reported a slight right-hand advantage. Brodie (1985) found a slight left-hand advantage for right-handed male subjects, although he did not carry out a statistical analysis on the

This research was carried out at the University of Stirling and formed part of a thesis submitted for the degree of $\mathrm{PhD}$. It was supported by a grant from the Carnegie Trust and by a grant from the Medical Research Council (U.K.) to H. E. Ross. The author's mailing address is: Department of Psychological Medicine, University of Glasgow, Glasgow G12 0AA, Scotland. data. However, if research into manual asymmetries and hemispheric specialization is taken into account, then predictions may be made regarding the existence and direction of an asymmetry for right-handed subjects: A left-hand advantage may be predicted if weight discrimination is subserved primarily by manipulospatial processes (Le Doux, 1983), and a right-hand advantage may be predicted if weight discrimination is subserved primarily by motor processes (Kimura, 1974).

Theories of weight perception generally involve the notion that the weight of an object is directly related to the amount of effort required to lift it. These sensationalistic theories are expressed in different variants based on either a "sense of effort" (McCloskey, Ebeling, \& Goodwin, 1974; Waller, 1891) or "sensations of innervation" (Wundt, 1892/1912), and they predict that stimulus weights of equal weight and size, when lifted with the preferred hand, will seem lighter than when lifted with the nonpreferred hand. This prediction is based on the assumption that the preferred hand can exert more force than the nonpreferred hand and therefore requires less effort to lift objects. A predictable bias, or constant error, is thus introduced into two-handed weight discrimination, although the effect on one-handed discrimination is less clear. Weber (1834/1978a, p. 57) suggested that weights feel heavier on the hand with better discrimination; however, this has not been established experimentally.

Shen (1935) investigated the constant error in twohanded weight perception using male and female subjects, but could not relate hand preference to the direction of the error for all of the subjects. Subsequently, Shen (1936) did report consistent right-hand underestimation of weight using only right-handed male subjects. However, Shen did not test left-handed subjects, female subjects, or the individual sensitivity of the left and right hands. Brodie (in press) investigated the direction of the constant error 
in two-handed simultaneous weight discrimination using left- and right-handed male and female subjects. Hand preference, as measured by the Edinburgh Handedness Inventory (EHI; Oldfield, 1971), correlated with neither the direction nor the degree of the error found. However, Brodie did find a sex difference, DLs for male subjects differed between left and right hands, whereas DLs for female subjects did not.

Sex differences have been found in a variety of perceptual and motor tasks, although the evidence in favor of superior male performance is not conclusive (Fairweather, 1976; Maccoby \& Jacklin, 1974). Studies investigating weight perception have found a trend toward poorer discrimination among females in one-handed discrimination (Gardner, Salaz, Reyes, \& Brake, 1983; Synodinos \& Ross, 1979), although no difference between the sexes has been found in two-handed discrimination (Brodie, in press). These findings are in keeping with the literature, which suggests more unilateral involvement for males and more bilateral involvement for females in perceptual tasks (e.g., McGlone, 1980).

An experiment was devised to investigate sex and handpreference effects in the one- and two-handed discrimination of lifted weight using left- and right-handed male and female subjects.

\section{METHOD}

\section{Subjects}

Sixty-six undergraduate students acted as subjects as part of a course requirement. There were 25 male and 41 female subjects. Their ages ranged from 17 to 54, with a mean of 21 .

\begin{abstract}
Apparatus
Two sets of stimulus weights were used. Each set of weights consisted of 7 standard weights and 7 comparison weights. The standard weights weighed $50 \mathrm{~g}$ and the comparison weights ranged from 52 to $64 \mathrm{~g}$ in $2-\mathrm{g}$ increments. All the weights were identical cylinders $(4.5 \times 2.5 \mathrm{~cm})$ constructed out of aluminum. Equal distribution of the material was ensured by the removal of a central core along the longer axis. An Apple II microcomputer, with a monochrome visual-display unit (VDU) and dual disk drive, was programmed to generate and randomly intersperse two up-down transformed response rules (UDTRRs) at the $70.7 \%$ correct level (Wetherill \& Levitt, 1965). The subjects were instructed via the VDU. The computer received the subjects' responses via pushbuttons, recorded their responses on floppy disks, and calculated DLs from 48 trials or 16 reversals, whichever occurred sooner. Two stimulus-bearing carousels were used to automatically present stimuli to the subjects' left or right hands in the order and at the intensity dictated by the UDTRRs. The use of a microcomputer in conjunction with stimulusbearing carousels to automatically present stimulus weights to subjects is fully described elsewhere (Brodie, 1985).
\end{abstract}

\section{Procedure}

The subjects sat in front of the carousels and the armrests were placed in position. Hand preference was measured using the EHI and was expressed as a laterality quotient (LQ) between -100 (strong left-hand preference) and +100 (strong right-hand preference) (Oldfield, 1971). The experimenter administered the EHI at the start of the test session and ensured its correct completion. The subjects were given a set of instructions via the VDU for the oneand two-handed discrimination paradigms and then were tested in three conditions in turn, with the order counterbalanced.
Two of the three paradigms involved one-handed consecutive weight discrimination with DLs measured for both the left hand (LH) and the right hand (RH). DLs were calculated using the UDTRRs for two order-of-presentation conditions: standard (lighter) weight first (SF) and standard weight second (SS). The third paradigm involved two-handed simultaneous weight discrimination (TH). DLs were calculated for the two sides of presentation conditions: standard (lighter) weight left (SL) and standard weight right (SR).

During the test session, the command to lift and lower the stimulus weights and the command to respond were flashed on the screen. The experimenter ensured that the subjects followed the commands promptly and consistently. This enabled control of a 3-sec stimulus presentation time for all the paradigms and a 5-sec interstimulus interval for the consecutive paradigm. In the consecutive paradigm, the subjects pressed the button on the nonlifting side to obtain the second stimulus weight; they recorded their "heavier" response by pressing Button 1 if the first weight was heavier and Button 2 if the second weight was heavier. In the simultaneous paradigm, the subjects recorded their "heavier" responses by pressing the right-hand button if the right weight was heavier and the left-hand button if the left weight was heavier. The test session lasted approximately $1 \mathrm{~h}$ and $30 \mathrm{~min}$.

\section{RESULTS}

Of the 66 subjects tested, 9 female subjects were lefthanded, with LQs ranging from -100 to -13 , and 32 were right-handed, with LQs ranging from +13 to +100 . Nine male subjects were left-handed, with LQs ranging from -100 to -14 , and 16 were right-handed, with LQs ranging from +50 to +100 . All subjects with positive LQs used only their right hands for writing and drawing; all subjects with negative LQs used only their left hands for writing and drawing.

The DLs calculated from the three discrimination paradigms-LH, $\mathrm{RH}$, and TH-are shown in Table 1.

An analysis of variance (ANOVA) was performed on the DLs from the one-handed paradigm with two betweensubject variables: sex (S), which had two levels (male and female), and hand preference (HP), which had two levels (left and right). There were two within-subject variables: hand $(\mathrm{H})$, which had two levels (left and right), and order of presentation (OOP), which had two levels (SF and SS). A significant main effect was found for $\operatorname{HP}[F(1,62)=$ $4.90, p<.05$ ] due to left-handed subjects' (mean DL $=5.00$ ) performing better than right-handed subjects (mean DL $=5.51$ ) with both right and left hands. A significant main effect was found for $\operatorname{OOP}[F(1,62)=67.32$, $p<.01]$ because DLs were lower for SF presentations $(\mathrm{DL}=4.31)$ than for SS presentations $(\mathrm{DL}=6.20)$. A significant interaction between $\mathrm{H}$ and $\mathrm{S}$ was found $[F(1,62)=4.7, p<.05]$ due to the fact that left- and right-handed females were better with their right hands $(\mathrm{DL}=5.19)$ than with their left hands $(\mathrm{DL}=5.45)$, and left- and right-handed males were better with their left hands $(\mathrm{DL}=4.95)$ than with their right hands $(\mathrm{DL}=$ 5.43). A significant interaction between $O O P$ and $H$ was found $[F(1,62)=11.18, p<.01]$ due to the fact that the left-hand difference between SF (DL = 3.93) and SS $(\mathrm{DL}=6.47)$ was more pronounced than the right-hand difference between SF (DL $=4.69)$ and SS $(\mathrm{DL}=5.93)$. 
Table 1

Differential Thresholds (in grams) for the One- and Two-Handed Discrimination of Lifted Weight

\begin{tabular}{|c|c|c|c|c|c|c|c|}
\hline \multirow[b]{3}{*}{ Sex } & \multirow{3}{*}{$\begin{array}{c}\text { Hand } \\
\text { Preference }\end{array}$} & \multirow[b]{3}{*}{ Hand } & \multicolumn{4}{|c|}{ Order/Side of Presentation } & \multirow[b]{3}{*}{ Mean } \\
\hline & & & \multicolumn{2}{|c|}{$\mathrm{SF} / \mathrm{SL}$} & \multicolumn{2}{|c|}{ SS/SR } & \\
\hline & & & $M$ & $S D$ & $M$ & $\overline{S D}$ & \\
\hline Male & Right & $\begin{array}{l}\text { Left } \\
\text { Right } \\
\text { Both }\end{array}$ & $\begin{array}{l}3.89 \\
5.50 \\
6.33\end{array}$ & $\begin{array}{l}0.63 \\
1.57 \\
2.89\end{array}$ & $\begin{array}{l}6.56 \\
5.51 \\
4.83\end{array}$ & $\begin{array}{l}1.97 \\
1.64 \\
2.95\end{array}$ & $\begin{array}{l}5.23 \\
5.51 \\
5.58\end{array}$ \\
\hline Male & Left & $\begin{array}{l}\text { Left } \\
\text { Right } \\
\text { Both }\end{array}$ & $\begin{array}{l}3.34 \\
4.59 \\
6.64\end{array}$ & $\begin{array}{l}0.91 \\
0.95 \\
4.08\end{array}$ & $\begin{array}{l}5.99 \\
6.12 \\
3.63\end{array}$ & $\begin{array}{l}2.21 \\
2.17 \\
2.26\end{array}$ & $\begin{array}{l}4.67 \\
5.36 \\
5.14\end{array}$ \\
\hline Female & Right & $\begin{array}{l}\text { Left } \\
\text { Right } \\
\text { Both }\end{array}$ & $\begin{array}{l}4.17 \\
4.64 \\
5.57\end{array}$ & $\begin{array}{l}0.96 \\
0.81 \\
3.73\end{array}$ & $\begin{array}{l}7.50 \\
6.30 \\
5.53\end{array}$ & $\begin{array}{l}2.04 \\
1.62 \\
3.57\end{array}$ & $\begin{array}{l}5.83 \\
5.47 \\
5.55\end{array}$ \\
\hline Female & Left & $\begin{array}{l}\text { Left } \\
\text { Right } \\
\text { Both }\end{array}$ & $\begin{array}{l}4.31 \\
4.02 \\
4.13 \\
\end{array}$ & $\begin{array}{l}1.07 \\
0.79 \\
3.51\end{array}$ & $\begin{array}{l}5.84 \\
5.79 \\
7.49 \\
\end{array}$ & $\begin{array}{l}1.55 \\
1.65 \\
3.21 \\
\end{array}$ & $\begin{array}{l}5.08 \\
4.91 \\
5.81 \\
\end{array}$ \\
\hline
\end{tabular}

Note-Order of presentation: SF, standard first; SS, standard second. Side of presentation: SL, standard left; SR, standard right.

A significant three-way interaction of OOP $\times \mathrm{H} \times \mathrm{HP}$ was found $[F(1,62)=4.92, p<.05]$ due to the fact that the difference between SF and SS was more pronounced for the left hand in right-handed subjects (see Table 2).

In order to compare DLs for one- and two-handed discrimination, an ANOVA was performed on the mean thresholds for $\mathrm{LH}, \mathrm{RH}$, and $\mathrm{BH}$. There were two betweensubject variables: sex (S), which had two levels (male and female), and hand preference (HP), which had two levels (left and right). No significant effects were found, although two-handed discrimination did produce slightly poorer performance on average $(\mathrm{DL}=5.52)$ than onehanded discrimination using either the left $(\mathrm{DL}=5.20)$ or right $(\mathrm{DL}=5.31)$ hand.

An ANOVA was performed on the DLs for the twohanded simultaneous discrimination test. No significant main effects were found. One significant interaction was found between side of presentation and sex $[F(1,62)=$

Table 2

Analysis of Variance of Mean Differential Thresholds for the One-Handed Discrimination of Lifted Weight

\begin{tabular}{|c|c|c|}
\hline Source & $d f$ & $F$ \\
\hline $\begin{array}{l}S \\
H P \\
S \times H P\end{array}$ & $\begin{array}{l}1,62 \\
1,62 \\
1,62\end{array}$ & $\begin{array}{l}0.34 \\
4.90^{*} \\
0.45\end{array}$ \\
\hline $\begin{array}{l}H \\
H \times S \\
H \times H P \\
H \times S \times H P\end{array}$ & $\begin{array}{l}1,62 \\
1,62 \\
1,62 \\
1,62\end{array}$ & $\begin{array}{l}0.40 \\
4.70^{*} \\
0.73 \\
0.10\end{array}$ \\
\hline $\begin{array}{l}\text { OOP } \\
\text { OOP } \times \mathrm{S} \\
\mathrm{OOP} \times \mathrm{HP} \\
\mathrm{OOP} \times \mathrm{S} \times \mathrm{HP}\end{array}$ & $\begin{array}{l}1,62 \\
1,62 \\
1,62 \\
1,62\end{array}$ & $\begin{array}{c}67.32 \ddagger \\
0.60 \\
0.01 \\
2.97\end{array}$ \\
\hline $\begin{array}{l}H \times \text { OOP } \\
H \times \text { OOP } \times S \\
H \times \text { OOP } \times H P \\
H \times O O P \times S \times H P\end{array}$ & $\begin{array}{l}1,62 \\
1,62 \\
1,62 \\
1,62\end{array}$ & $\begin{array}{l}11.18 \dagger \\
2.24 \\
4.92^{*} \\
0.05\end{array}$ \\
\hline
\end{tabular}

Note-S $=$ sex; $H P=$ hand preference; $H=$ hand; $O O P=$ order of presentation. ${ }^{*} p<.05 . \quad \dagger p<.01 . \quad \ddagger p<.001$.
$5.17, p<.05]$. This interaction was due to the fact that SL presentations $(D L=6.44)$ were significantly higher than SR presentations (DL $=4.40$ ) for male subjects $[t(24)=1.97, p<.05$, one tail $]$, whereas SR presentations $(\mathrm{DL}=5.96)$ did not differ from SL presentations $(\mathrm{DL}=5.25)$ for female subjects $[t(40)=-0.68$, $p>.05$, one tail].

Correlations were calculated between LQs and DLs for male and female subjects. For male subjects, no significant correlation was found between hand preference and DLs for either the right or the left hand. Female subjects did show a significant correlation $(r=.3719, n=41$, $p<.05$ ) between hand preference and right-hand performance, but not between hand preference and left-hand performance.

In order to test whether hand sensitivity and the direction of bias in the two-handed paradigm was related, a correlation was calculated on the difference score between DLs for RH and LH in the one-handed paradigm and the difference score between DLs for SL and SR in the twohanded paradigm. No significant effect was found for either male or female subjects.

\section{DISCUSSION}

The results clearly show that DLs calculated in twohanded simultaneous weight lifting display a constant error. Handedness, as measured by the EHI, did not correlate with the direction or the degree of this error. That is, subjects using their preferred hands did not consistently under- or overestimate the weight, and subjects with a strong hand preference did not show more of an error than subjects with a weaker hand preference. A difference in the direction of the constant error was found betewen the sexes: Male subjects produced significantly lower DLs when the standard weight was in the right hand and females produced nonsignificantly lower DLs when the standard weight was in the left hand. The direction and degree of this sex difference had been found previously (Brodie, in press) and may reflect the fact that females are less lateralized in brain function than males (De Renzi, 1982; Harris, 1978).

Male subjects performed better in one-handed discrimination with the left hand and found weights heavier in the left hand in two-handed discrimination. Female subjects performed better with the right hand in one-handed discrimination but did not find weights heavier in either hand in two-handed discrimination. The relationship between hand sensitivity and direction of error was not statistically significant. However, it does tend to suggest that there may be a relationship between hand sensitivity in onehanded weight discrimination and the direction of bias in two-handed weight discrimination for male subjects, an explanation first suggested by Weber (1834/1978a). A problem with the experimental methodology (the need to ensure that the subjects performed a perfectly simultaneous lifting movement of left and right hands in the twohanded discrimination paradigm) and the large number 
of right-handed female subjects may explain the difficulty in obtaining statistical significance.

In one-handed discrimination, DLs were found to be lower when the standard weight was presented first than when the standard weight was presented second. This finding reflects a constant error known as the time error (Fechner, 1860/1966; Needham, 1934; Ross, 1964). More recently it has been renamed the time order error (TOE) to avoid confusion with errors occurring in time estimation (Hellström, 1985). The TOE is a bias that causes subjects, when presented with two consecutively presented stimuli of equal intensity, to find one stimulus less intense than the other. The TOE is defined as being positive when the second stimulus is found less intense and negative when the first stimulus is found less intense. In the onehanded weight discrimination paradigm, there were more second-heavier responses, resulting in a lowering of the threshold when this was the correct response (i.e., when the comparison [heavier] weight was second) and resulting in a raising of the threshold when this was the incorrect response (i.e., when the standard [lighter] weight was presented second). This negative direction of the TOE is well known (e.g., Brown, 1910; Needham, 1934; Ross, 1964), with the bias being to more second-heavier responses. A change in the direction of the TOE has been attributed to many factors (e.g., length of interstimulus interval, stimulus intensity, difficulty of task). However, in the present experiments it always remained negative. In fact, the evidence suggests that the mechanisms subserving weight discrimination may account for the size of effect; the magnitude of the TOE was largest for male subjects using the nonpreferred hand. This supports the hypothesis that the TOE is a perceptual phenomenon rather than a response bias (Hellström, 1985).

Reviews of the literature investigating hand preference and manual performance (Hicks \& Kinsbourne, 1978; Porac \& Coren, 1981) suggest that investigators have had difficulty in specifying the relationship between hand preference and hand proficiency in a variety of tasks. However, it is generally thought that right-handers are more skillful at manual tasks with the right hand than are left-handers with the left hand. It is also thought that lefthanders display greater variability (Hicks \& Kinsbourne, 1978 , p. 537). For purposes of weight discrimination, hand preference and hand proficiency are not related. Many right-handed subjects performed better with the left hand, and many left-handed subjects performed better with the right hand.

Surprisingly, left-handed subjects performed significantly better than right-handed subjects with both the left and right hands in one-handed weight discrimination. This advantage in performance for subjects with a left-hand preference was found recently in a peg-pulling task (Kilshaw \& Annett, 1983). It suggests that hemispheric specialization is an important factor in the determination of advantages in tasks requiring manipulation of objects in time and space, such as peg pulling or weight discrimi- nation, because of the contralateral control of the upper limbs. Among right-handed populations, it has been found that approximately $90 \%$ have language lateralized to the left hemisphere, resulting in the preferred hand's normally being contralateral to the language hemisphere. In a small proportion of the right-handed population, the hemisphere that processes spatial information is contralateral to the preferred hand; in a much larger proportion of the left-handed population, the preferred hand is contralateral to the spatial hemisphere (Gazzaniga \& Le Doux, 1978; Milner, 1974). Thus, right-handed male subjects would be expected to have better weight discrimination with the nonpreferred hand, since it is contralateral to the nonlanguage hemisphere. Although a left-hand advantage was found for right-handed male subjects, it did not prove to be statistically significant. Since there is evidence to suggest that hand preference may not reflect cerebal asymmetry (Beaumont, 1983; Strauss, 1986), an independent measure of cerebral asymmetry would be required to test for right-hemisphere processing for language among the right-handed subjects used. Brodie (1987) used a consonant-vowel dichotic listening test in an experiment designed to relate hand proficiency in weight discrimination to the lateralization of cerebral function. He found DLs to be lower in the spatial field contralateral to the ear that proved superior in the dichotic listening task.

The results of the two-handed weight-discrimination paradigm may be explained in terms of theories of bimanual motor control (e.g., Kelso, Putnam, \& Goodman, 1983; Peters, 1985). In these theories, a single high-level integrative mechanism is responsible for coordinating the activity of both upper limbs. Such a mechanism would allow the muscle activity of both hands to be organized into a single functional unit in order to produce simultaneity of movement. Under such conditions, the afference necessary to signal the weight of the lifted object in each hand would not find a suitable comparison efference. It is thus likely that such a system cannot cope with the demands of simultaneity of both motor output and sensory input.

The error may also be explained in terms of attention. Weber (1834/1978a) and Fechner (1860/1966, p. 73) advocated such an explanation by arguing that attention in two-handed simultaneous weight lifting inevitably centers on one or the other hand. Peters (1985) suggested that attention was an important factor in the interaction between the two levels of his model of bimanual motor control. Thus, to achieve a two-handed simultaneous lifting movement, attention is first turned to the high-level mechanism. To attend to the weight of the object in each hand in order to perform the discrimination, attention must turn to the low-level mechanisms. Such attentional shifts may not be conducive to weight discrimination. The comparison of two-handed simultaneous and two-handed consecutive discrimination paradigms would be necessary to test this hypothesis. 


\section{REFERENCES}

Beaumont, J. G. (1983). Method for studying cerebral hemispheric function. In A. W. Young (Ed.), Functions of the right cerebral hemisphere (pp. 113-146). London: Academic Press.

BrodiE, E. E. (1985). The measurement of differential thresholds for lifted weights by microcomputer controlled apparatus. Perception, 14, 371-376.

BRODIE, E. E. (1987). Manual asymmetry in weight discrimination: Hand preference, hemispheric specialisation or hemispace? Manuscript submitted for publication.

Brodie, E. E. (in press). Sex and hand preference effects in two-handed simultaneous weight discrimination. American Journal of Psychology.

Brodie, E. E., \& Ross, H. E. (1984). Sensorimotor mechanisms in weight discrimination. Perception \& Psychophysics, 36, 477-481.

Brodie, E. E., \& Ross, H. E. (1986). Degrees of freedom of movement in weight discrimination: Effect of stimulus intensity. In B. Berglund, U. Berglund, \& R. Teghtsoonian (Eds.), Fechner Day 86 (pp. 15-20). Stockholm: International Society for Psychophysics.

Brown, T. (1910). The judgment of difference with special reference to the doctrine of the threshold in the case of lifted weights. University of California Publications in Psychology, 1, 1-77.

CoRKIN, S. (1978). The role of different cerebral structures in somesthetic perception. In E. C. Carterette \& M. P. Friedman (Eds.), Handbook of perception: Vol. 6B. Feeling and hurting (pp. 106-147). New York: Academic Press.

Corkin, S., Milner, B., Rasmussen, T. (1970). Somatosensory thresholds. Archives of Neurology, 23, 41-58.

DE RENZI, E. (1982). Disorders of space exploration and cognition. New York: Wiley.

Fairweather, H. (1976). Sex differences in cognition. Cognition, 4, 231-280.

FECHNER, G. T. (1966). Elements of psychophysics (Vol. 1; H. E. Adler, Trans.). New York: Holt, Rinehart \& Winston. (Original work published 1860)

Gardner, R. M., Salaz, V., Reyes, B, \& Brake, S. J. (1983). Sensitivity to proprioceptive feedback in obese subjects. Perceptual \& Motor Skills, 57, 1111-1118.

Gazzaniga, M. S., \& Le Doux, J. E. (1978). The integrated mind. New York: Plenum Press.

HaRRIS, J. L. (1978). Sex differences in spatial ability: Possible environmental, genetic, and neurological factors. In M. Kinsbourne (Ed.), Asymmetrical function of the brain (pp. 405-522). New York: Cambridge University Press.

Hellström, A. (1985). The time-order error and its relatives: Mirrors of cognitive processes in comparing. Psychological Bulletin, 97, 35-61.

Hicks, R. E., \& KinsBourne, M. (1978). Human handedness. In M. Kinsbourne (Ed.), Asymmetrical function of the brain (pp. 523-549). New York: Cambridge University Press.

Kelso, J. A. S., Putnam, C. A., \& Goodman, D. (1983). On the spacetime structure of human interlimb co-ordination. Quarterly Journal of Experimental Psychology, 35A, 347-375.

KILSHAW, D., \& ANNETT, M. (1983). Right- and left-hand skill: I. Effects of age, sex and hand preference showing superior skill in lefthanders. British Journal of Psychology, 74, 253-268.
Kimura, D. (1974). Motor functions of the left hemisphere. Brain, 97, 337-350.

LE Doux, J. E. (1983). Cerebral asymmetry and the integrated function of the brain. In A. W. Young (Ed.), Functions of the right cerebral hemisphere (pp. 203-216). London: Academic Press.

MACCOBY, E. E., \& JACKLIN, C. N. (1974). The psychology of sex differences. Stanford, CA: Stanford University Press.

McCloskey, D. I., Ebeling, P., \& Goodwin, G. M. (1974). Estimations of weights and tensions and apparent involvement of a "sense of effort." Experimental Neurology, 42, 220-232.

McGlone, J. (1980). Sex differences in human brain asymmetry: A critical survey. Behavior \& Brain Science, 3, 215-227.

MiLner, B. (1974). Hemispheric specialization: Scope and limits. In F. O. Schmitt \& F. G. Worden (Eds.), The neurosciences (pp. 7589). Cambridge, MA: MIT Press.

Needham, J. G. (1934). The time-error in comparison judgments. Psychological Bulletin, 31, 229-243.

OLdFIELD, R. C. (1971). The assessment and analysis of handedness: The Edinburgh Inventory. Neuropsychologia, 9, 97-113.

PETERs, M. (1985). Constraints in the performance of bimanual tasks and their expression in unskilled and skilled subjects. Quarterly Journal of Experimental Psychology, 37A, 171-196.

PORAC, C., \& COREN, S. (1981). Lateral preferences and human behavior. New York: Springer-Verlag.

Ross, H. E. (1964). Constant errors in weight judgments as a function of the differential threshold. British Journal of Psychology, 55, 133-141.

SHEN, N. C. (1935). Simultaneous lifting of equally heavy weights by both right and left hands. Joumal of Experimental Psychology, 18, 544-561.

SHEN, N. C. (1936). Handedness effects in simultaneous lifting of weights by both hands. Journal of Experimental Psycholgoy, 19, 64-76.

STRAuss, E. (1986). Hand, foot, eye and ear preferences and performance on a dichotic listening test. Cortex, 12, 475-482.

Synodinos, N. E., \& Ross, H. E. (1979). Water temperature and weight discrimination. Ergonomics, 22, 1083-1093.

WALLER, A. D. (1891). The sense of effort: An objective study. Brain, 14, 179-249.

WEBER, E. H. (1978a). De subtilitate tactus (H. E. Ross, Trans.). In The sense of touch (pp.19-135). London: Academic Press. (From De pulsu, resorptione, audito et tactu. Leipzig: Koehler, 1834)

WEBER, E. H. (1978b). Der Tastsinn und das Gemeingefühl (D. J. Murray, Trans.). In The sense of touch (pp. 139-264). London: Academic Press. (From Handwörterbuch der Physiologie [Vol. 3]. Brunswick: Vieweg, 1846)

WeTHERILl, G. B., \& LeVITT, H. (1965). Sequential estimations of points on a psychometric function. British Journal of Mathematical \& Statistical Psychology, 18, 1-10.

WUNDT, W. (1912). Vorlesungen über die Menschen und Tierseele (2nd ed.; J. E. Creighton \& E. B. Titchner, Trans.). In Lectures on human and animal psychology (pp. 1-459). London: George Allen. (Original work published 1892)

(Manuscript received June 19, 1987; revision accepted for publication August 15, 1987.) 